\title{
FEM AND EXPERIMENTAL BASED ANALYSIS OF THE STAMPING PROCESS OF ALUMINUM ALLOY
}

\author{
Patryk Różyło', Łukasz Wójcik ${ }^{1}$ \\ 1 Lublin University of Technology, Mechanical Engineering Faculty, 36 Nadbystrzycka Str., 20-618 Lublin, \\ Poland, e-mail: p.rozylo@pollub.pl, I.wojcik@pollub.pl
}

Received: 2017.05.15

Accepted: 2017.08.01

Published: 2017.09.03

\begin{abstract}
The subject of the study was aluminum samples of varying thickness. The aim of the study was to perform the experimental stamping process of the samples on a universal testing machine and a numerical analysis on two independent computer systems Abaqus ${ }^{\circledR}$ and Deform-3D. As part of the numerical analysis, bilinear material model was included, taking into account elastic and plastic characteristics. The study was conducted in a dynamic environment with geometric nonlinearity. The results obtained from experimental research were confronted with those obtained by FEM computer simulation. During the research, numerical model of the stamping process has been developed, which was validated with the results of experimental research.
\end{abstract}

Keywords: pressing, experimental study, numerical analysis, finite element method.

\section{INTRODUCTION}

Modern times have allowed to introduce many changes to the sheet metal stamping technology. The most important change is the development of advanced computer techniques supporting the design of plastic forming processes. The application of numerical calculations and simulation software have allowed for significant costs reduction of design and preliminary testing of stamping processes. These systems help in the design phase and during the production cycle. Advanced simulation software are mainly used to predict the direction of flow of metal, of stress distribution analysis, deformation, temperature or possible defects. There are many different CAE / FEM software options available today on the market that allow computer-based analysis of metal forming processes.

Sheet metal forming is one of the most popular methods of forming thin-walled elements. Sheet metal forming includes many different processes i.e.: the processes that take into account friction $[5,6]$, but mainly cold plastic forming pro- cesses. A detailed classification of the stamping process is presented in [10]. Stamping is a sheet metal forming process consisting of converting a flat semi-finished product into a non-expandable piece. Elements obtained during a stamping process can be divided into three main groups: axially symmetric shape [7, 8], box shaped [2], complex symmetrical shape [9].

The stamping process of thin sheets constitutes a challenge for designers, caused by the radial stretching tensions and peripheral compression stresses, in the deformed lower part of the draw piece - uni-axial stretch, while the biaxial stresses in the bottom are extruded. It is assumed that the process is carried out in a two dimensional stress state.

Analysis of the stamping process is based on determining the occurring phenomena and interaction between the drawing and stretching areas. The analysis of phenomena occurring during sheet metal stamping is described in publication [4].

The stamping process is burdened with two major constraints that negatively affect the shaping of the sheet. The phenomena restricting the 
extrusion process are the corrugating of the draw piece flange and bursting of the cylindrical part of the draw piece wall. Corrugation of the draw piece flange is caused by loss of material stability in the area where the extruded material does not have contact with the blank holder. In order to increase the contact surface between the material and the blank holder, traction thresholds were used. Penetration of the occurred crinkle into the gap between the stamp and the die may result in jamming of the draw piece, rupture of the base, or cracking of the die wall. The limitations causing draw piece or tool damage are described by the researchers in publications $[1,3]$. The corrugation phenomenon occurs mostly during the shaping of axially-symmetrical draw pieces. Future research will include optimizing processes [11]. Corrugation occurs when the percentage of the initial thickness and the blank sheet diameter meets the following condition:

$$
\begin{gathered}
\frac{g_{0}}{D_{0}} \cdot 100 \% \leq 4,5\left(1-m_{1}\right) \\
m_{1}=\frac{d}{D_{0}}
\end{gathered}
$$

where:

d - internal draw piece diameter,

$\mathrm{D}_{0}$ - blank sheet diameter,

$\mathrm{g}_{0}$ - blank sheet initial thickness,

$\mathrm{m}_{1}$ - extrusion coefficient.

\section{SUBJECT OF THE STUDY}

Four disc shaped aluminum alloy samples were the subjects of the study. Test samples were characterized by a fixed diameter of $50 \mathrm{~mm}$ and variable thicknesses of $0.47,0.9,1$ and $1.44 \mathrm{~mm}$. The graphical representation of the test sample is shown in Figure 1.

Test samples were characterized by specific material properties, consistent with the definition of the elastic-plastic model. The elasticity properties which were essential to describe the material model were based on two parameters - Young's modulus and Poisson's ratio. Within the plastic bilinear material characteristics, the plasticity and strength limits of the material and the deformation when strength limit is reached. Considering the dynamic processing of the material, it was necessary to define the material density parameter. All experimentally determined materials characteris-
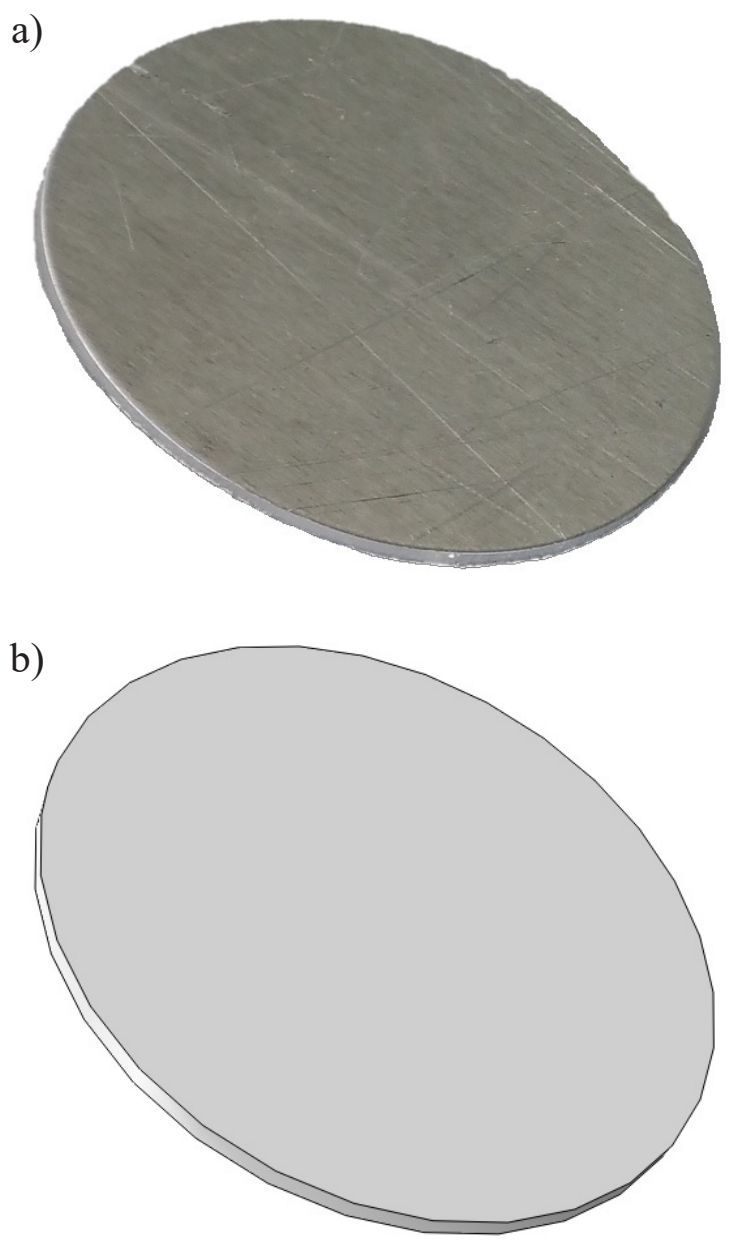

Fig. 1. Research sample: a) actual object, b) numerical model

Table 1. Material properties of the test sample (own study)

\begin{tabular}{|l|c|}
\hline \multicolumn{2}{|c|}{$\mathrm{Al}-1100$ aluminum material properties } \\
\hline Density $\rho\left[\mathrm{kg} / \mathrm{m}^{3}\right]$ & 2700 \\
\hline Young Modulus $[\mathrm{MPa}]$ & 70000 \\
\hline Poisson ratio $v[-]$ & 0.33 \\
\hline Yield point $\mathrm{R}_{\mathrm{e}}[\mathrm{MPa}]$ & 85 \\
\hline Tensile strength $\mathrm{R}_{\mathrm{m}}[\mathrm{MPa}]$ & 115 \\
\hline Elongation $\mathrm{A} \%[\%]$ & 2 \\
\hline
\end{tabular}

tics required for the correct implementation of the dynamic issue, particularly in the FEM analysis, are presented in Table 1.

\section{EXPERIMENTAL STUDIES}

Experimental studies were carried out on the Instron 3369 universal testing machine, used mainly for compression and stretching tests. Due to the nature of aluminum during the stamping 
a)
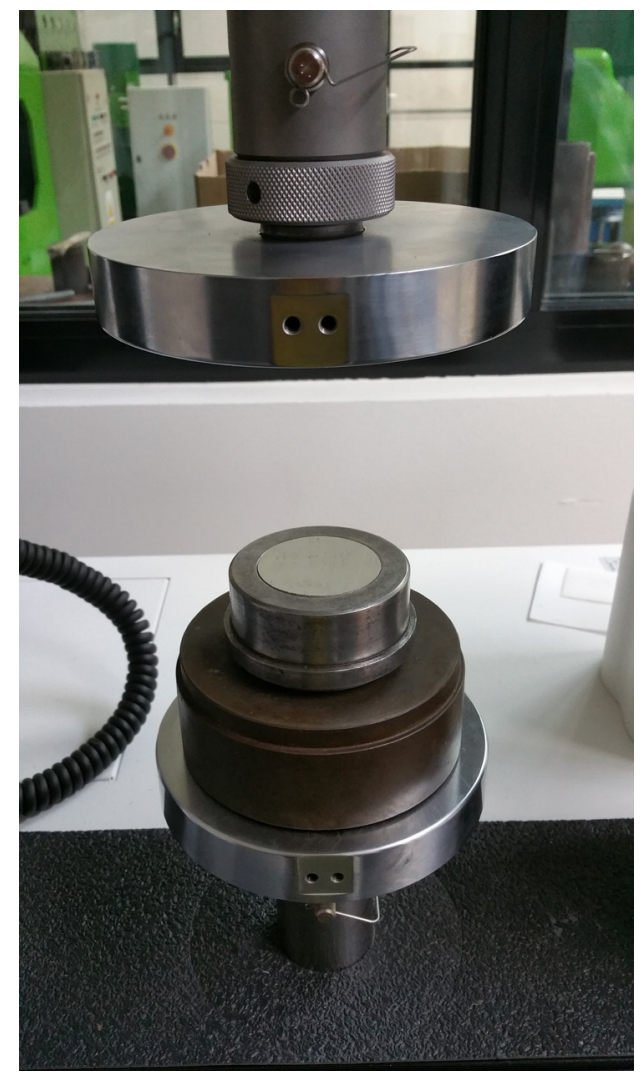

b)

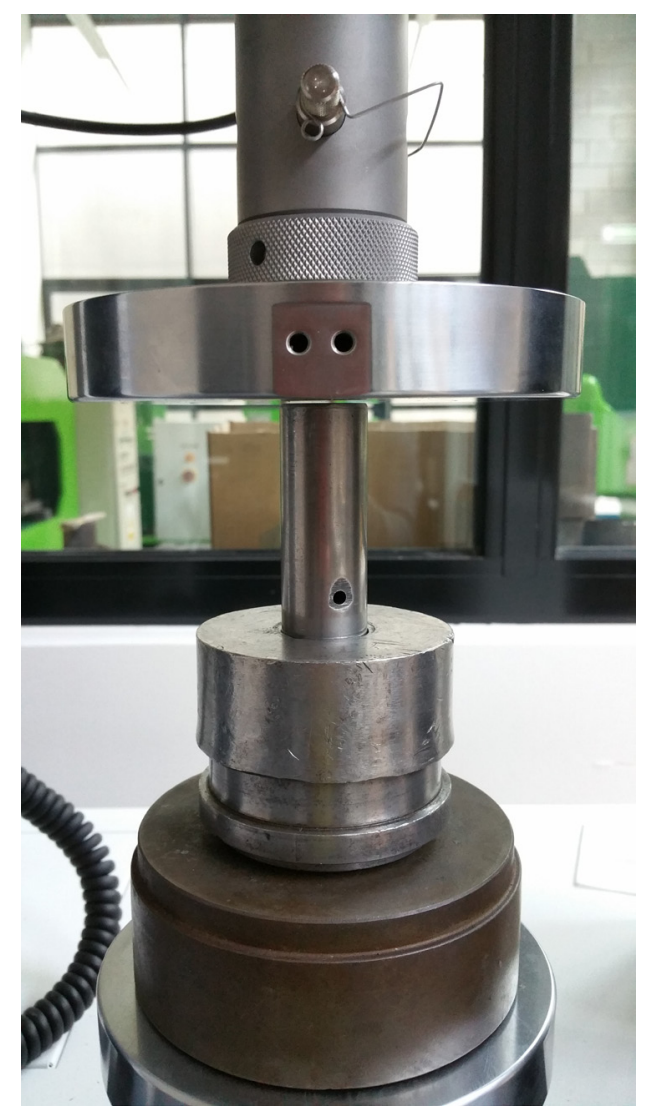

Fig. 2. Testing equipment set-up:

a) upper and lower head with matrix and test sample, b) complete form of test stand process it was necessary to adapt the test equipment accordingly. At the lower head of the testing machine, a die with test sample was properly placed inside. The upper die was equipped with an additional guide way for axial compression with respect to the stamp. Stamping process of prepared test samples was simulated by axial compression performed by universal testing machine. The sensor located in the upper head made it possible to measure the load-displacement ratio of the stamp as a result of the stamping process. The process was carried out with constant traverse speed of $1.67 \mathrm{~mm} / \mathrm{s}$. The traverse speed was set at a well-defined value, due to the necessity of stamp displacement by $65 \mathrm{~mm}$ in 38.92 seconds, in each test. The test equipment is shown in Fig. 2.

Experimental studies have allowed for obtaining draw pieces of different heights and thicknesses. As part of the performed tests, the load-displacement characteristics were obtained, showing the work done by the stamp during the process. Experimentally determined characteristics set the basis for further validation of FEM simulation results.

\section{NUMERICAL ANALYSIS}

Simulation studies were based on two independent finite elements numerical test environments, Abaqus and Deform-3D. In both cases it was necessary to generate components models that enabled the process to be carried out. Dimensioned 3D models (in [mm]), based on an actual objects are shown in Figure 3.

Initially, the numerical simulations of the material model were based on experimentally obtained data. The boundary conditions were defined with regard to the actual mounting of the components, in order to accurately simulate the process. The graphical representation of the respective boundary conditions used for the numerical analysis in both cases is shown on Fig. 4.

The numerical discretization was related to the use of the appropriate type of mesh type. In Abaqus, two types of numerical elements were used. The first, a R3D4 shell type mesh in which the finite element description is reduced to having 4 nodes within a single element and 3 degrees of freedom in each node. The mesh type used for non-deformable elements (30000 FE mesh), i.e.: for the die, guide way and stamp. Solid C3D8R element type has been used for aluminum sample (25000 FE mesh), which is a 3 degrees of freedom 
a)

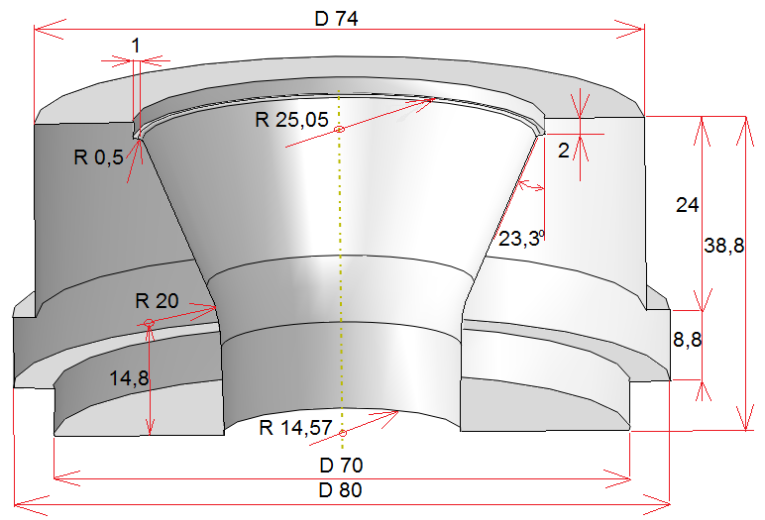

c)

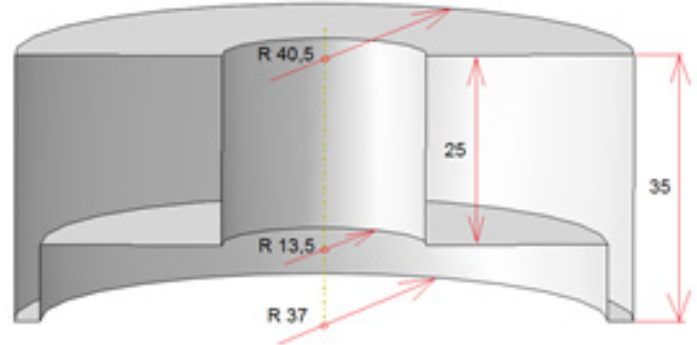

b)

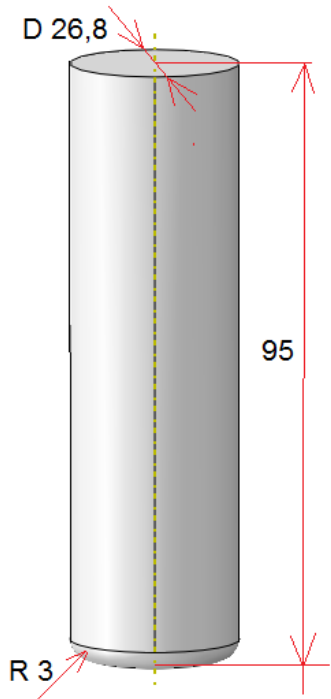

d)

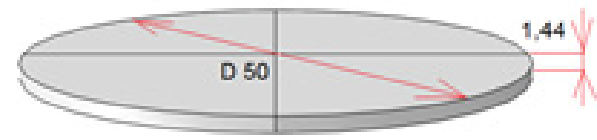

Fig. 3. Components of the testing equipment: a) die, b) stamp, c) guide way, d) test sample

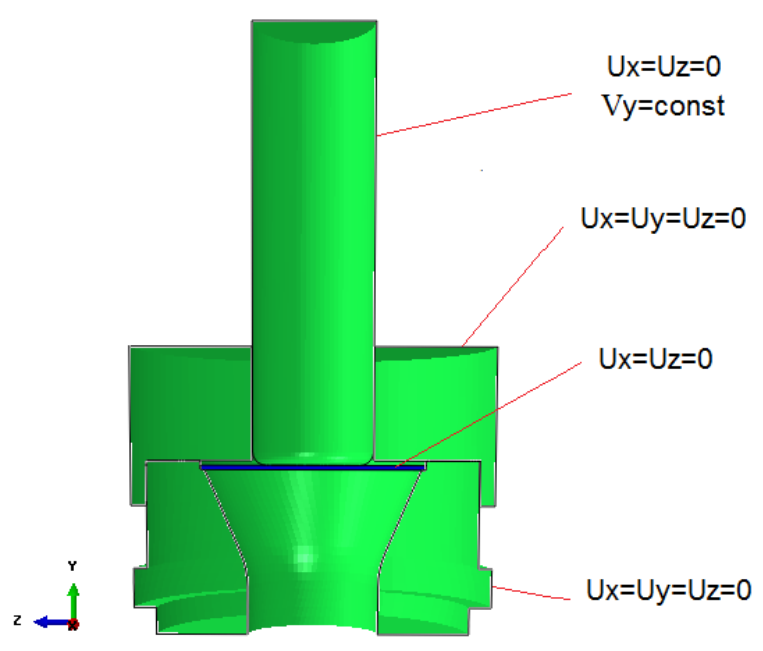

Fig. 4. Boundary conditions

element, 8 nodes, and is characterized by reduced integration - which allows for the removal of false forms of deformation during the process [12]. As for the Deform-3D system, the discretization of the prepared components was based on the use of solid tetrahedral FE mesh with high density (200000 FE mesh) to obtain accurate simulation results. Discrete model is shown in Figure 5.

Numerical analysis was based on the solution of the dynamic issue, under exactly the same conditions as the experimental study. The difference in modeling was mainly related to the type of mesh - solid and shell type in the Abaqus software and only solid in the Deform-3D.

\section{RESULTS}

Aluminum stamping process allowed to obtain the characteristics of the issue, in both experimental and the FEM studies. Graphical presentation of the simulation process, as a representation of the actual behaviour of the system, is shown on Fig. 6 and 7.

As part of the experimental and numerical analysis, it was possible to obtain draw pieces which were then compared on the basis of macroscopic examination and in the determination of the actual and simulated samples. Figure 8 shows a comparison of actual and numerical draw pieces.

The results obtained in a form of actual draw pieces and those obtained by simulations show very high correspondence. As a result of the macroscopic evaluation of the outcomes, a high convergence of the draw piece's shapes was demonstrated. In addition, the results of obtained height of the samples were compared according to their thickness and test type, as shown in Table 2. 

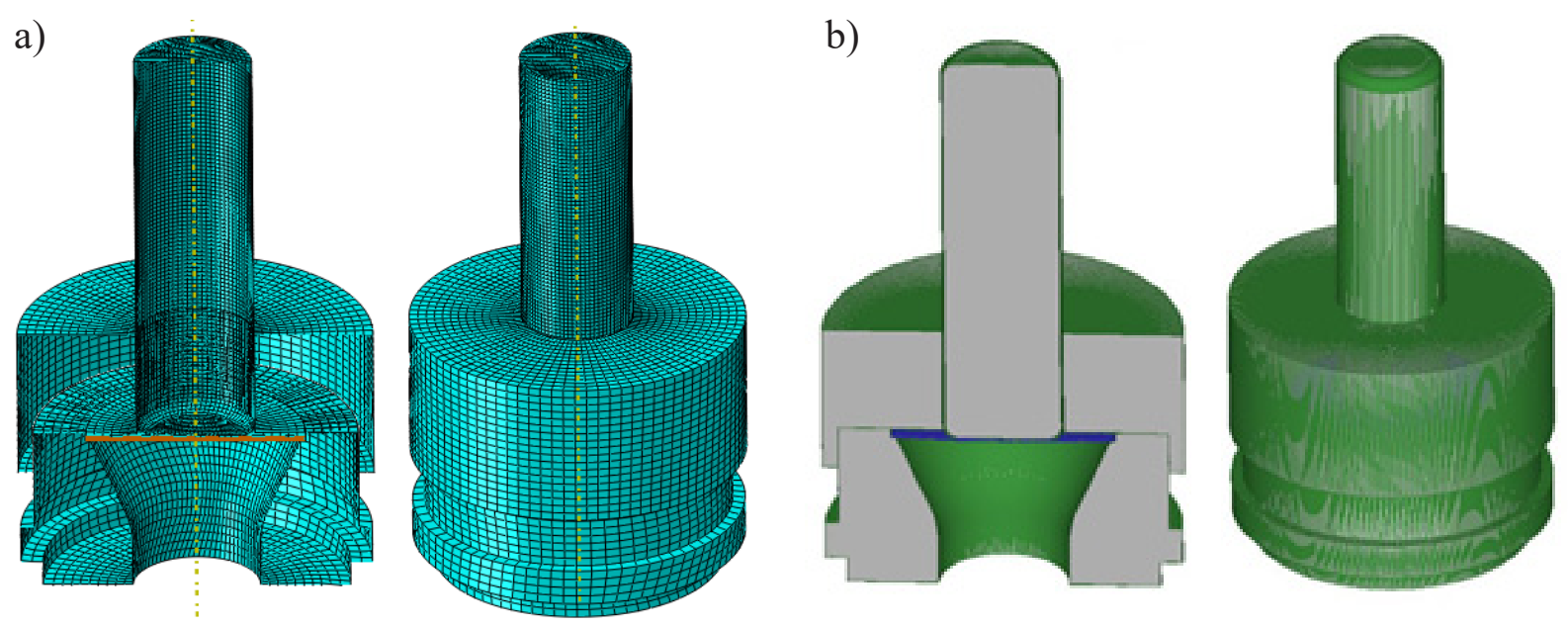

Fig. 5. Discrete model: a) Abaqus, b) Deform 3D
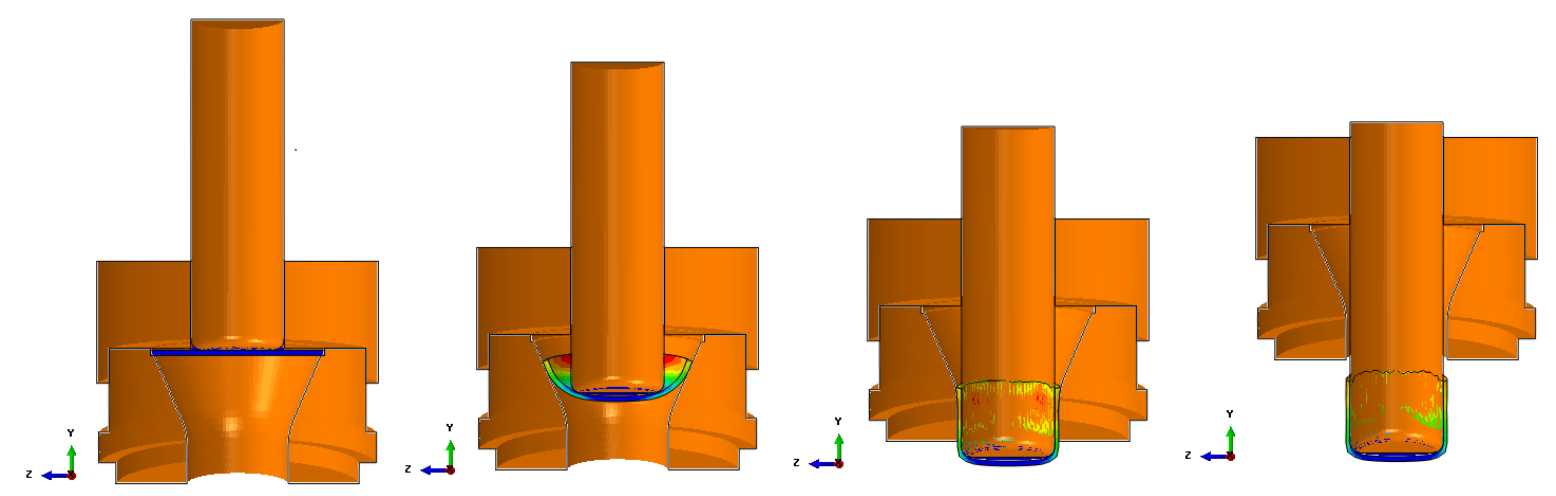

Fig. 6. Graphical presentation of the different stages of the stamping process - Abaqus
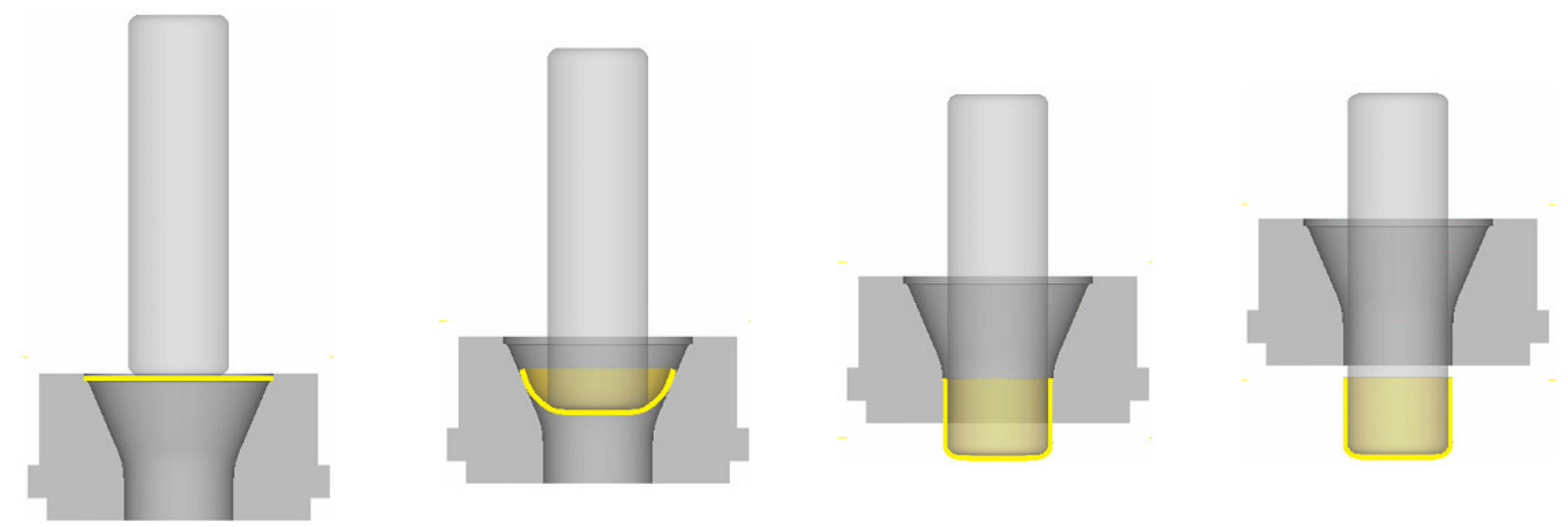

Fig. 7. Graphical presentation of the different stages of the stamping process - Deform-3D

Based on the conducted experimental and numerical studies, the operating characteristics of the system were determined for the process. Due to the fact that samples of 4 different thicknesses were taken in the consideration, a detailed verification of the obtained results was carried out. Comparison of stamping process characteristics in Fig. 9.

The presented characteristics of the stamping forces to the overlapping displacement of the stamp represent a high level of accuracy of the
Table 2. Summary of the height of the draw piece in regard to its thickness

\begin{tabular}{|c|c|c|c|c|}
\hline \multicolumn{2}{|c|}{} & $\begin{array}{c}\text { Actual } \\
\text { sample }\end{array}$ & $\begin{array}{c}\text { Abaqus } \\
\text { model }\end{array}$ & $\begin{array}{c}\text { Deform 3D } \\
\text { model }\end{array}$ \\
\hline $\begin{array}{c}\text { Sample } \\
\text { no. }\end{array}$ & $\mathrm{g}[\mathrm{mm}]$ & $\mathrm{h}[\mathrm{mm}]$ & $\mathrm{h}[\mathrm{mm}]$ & $\mathrm{h}[\mathrm{mm}]$ \\
\hline 1 & 0.47 & 13.2 & 13.3 & 13.75 \\
\hline 2 & 0.9 & 16.3 & 16.9 & 17.42 \\
\hline 3 & 1 & 16.5 & 17.4 & 17.85 \\
\hline 4 & 1.44 & 22.3 & 23.8 & 23.04 \\
\hline
\end{tabular}


a)
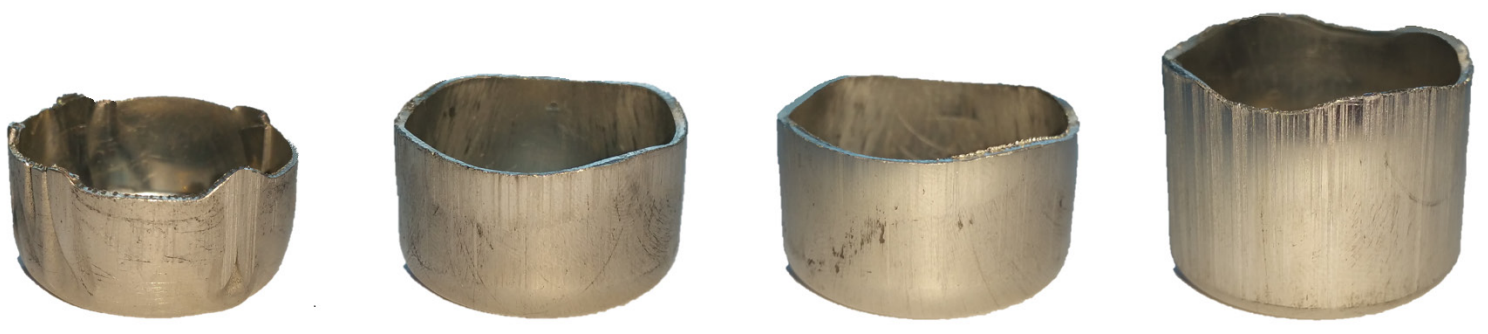

b)
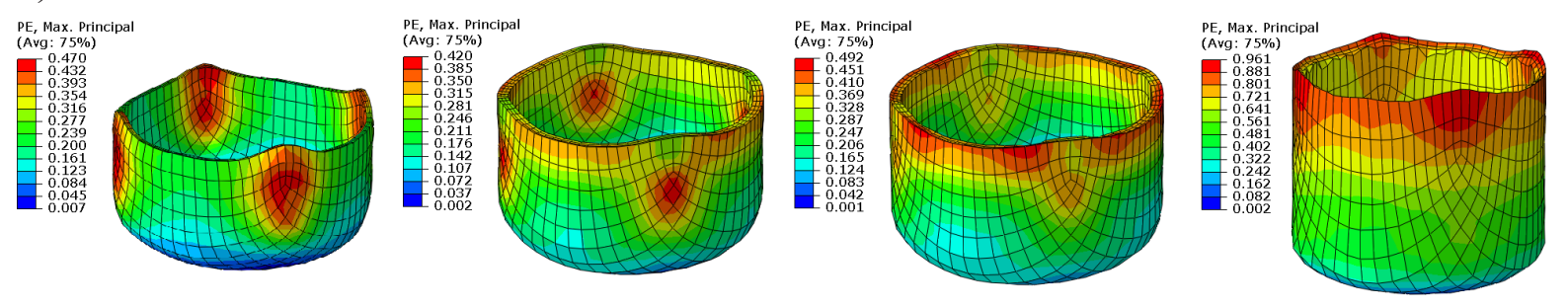

c)
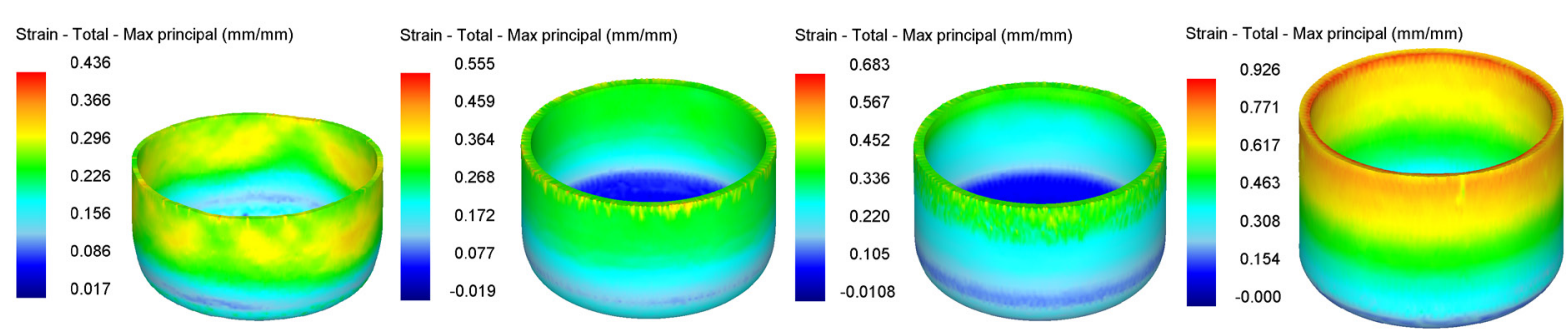

Fig. 8. Drawpieces obtained during stamping process: a) Actual objects, b) Abaqus numerical models, c) Deform-3D numerical models

Table 3. Comparison of the results of maximum stamping forces

\begin{tabular}{|c|c|c|c|c|c|}
\hline $\begin{array}{c}\text { Thickness } \\
{[\mathrm{mm}]}\end{array}$ & $\begin{array}{c}\text { Abaqus } \\
{[\mathrm{N}]}\end{array}$ & $\begin{array}{c}\text { Difference between } \\
\text { Abaqus and Experiment } \\
{[\%]}\end{array}$ & $\begin{array}{c}\text { Deform } \\
{[\mathrm{N}]}\end{array}$ & $\begin{array}{c}\text { Difference between Deform } \\
\text { and Experiment } \\
{[\%]}\end{array}$ & $\begin{array}{c}\text { Experiment } \\
{[\mathrm{N}]}\end{array}$ \\
\hline 0.47 & 3038.7 & 4.6 & 2853.7 & 10.4 & 3185.4 \\
\hline 0.9 & 5397.1 & 2 & 4922.5 & 6.9 & 5286.9 \\
\hline 1 & 7201.2 & 5.1 & 5741.1 & 16 & 6835.9 \\
\hline 1.44 & 18366.4 & 3.2 & 19445.4 & 8.6 & 17782.8 \\
\hline
\end{tabular}

numerically performed processes, in relation to the experimental research carried out. The obtained characteristics show relatively satisfactory quantitative and qualitative convergence within the obtained results. The displacement, at which the value of the stamping force is the greatest, increases with the thickness of the samples gains. For a $0.47 \mathrm{~mm}$ thickness of the sample, the load value is greatest with a displacement of about 30 $\mathrm{mm}$, while for a sample with a thickness of 1.44 $\mathrm{mm}$ the value of the stamping force has the highest value at a displacement of $40 \mathrm{~mm}$. Table 3 shows the results of maximum stamping forces in regard to the thickness of the test samples.
Based on the results presented in Table 3, a relatively high level of convergence of the obtained results of maximum sampling force has been exhibited. The confrontation of the results between two independent numerical analysis software and the experimental results clearly show that the level of results obtained differs significantly in relation to both software options. The smallest difference in results between experimental and numerical calculations based on the Abaqus system is $2 \%$, while the maximum divergence is $5.1 \%$. The highest correspondence between the experimental and the Deform calculations is $6.9 \%$, with a maximum variance of $16 \%$. Despite the same 

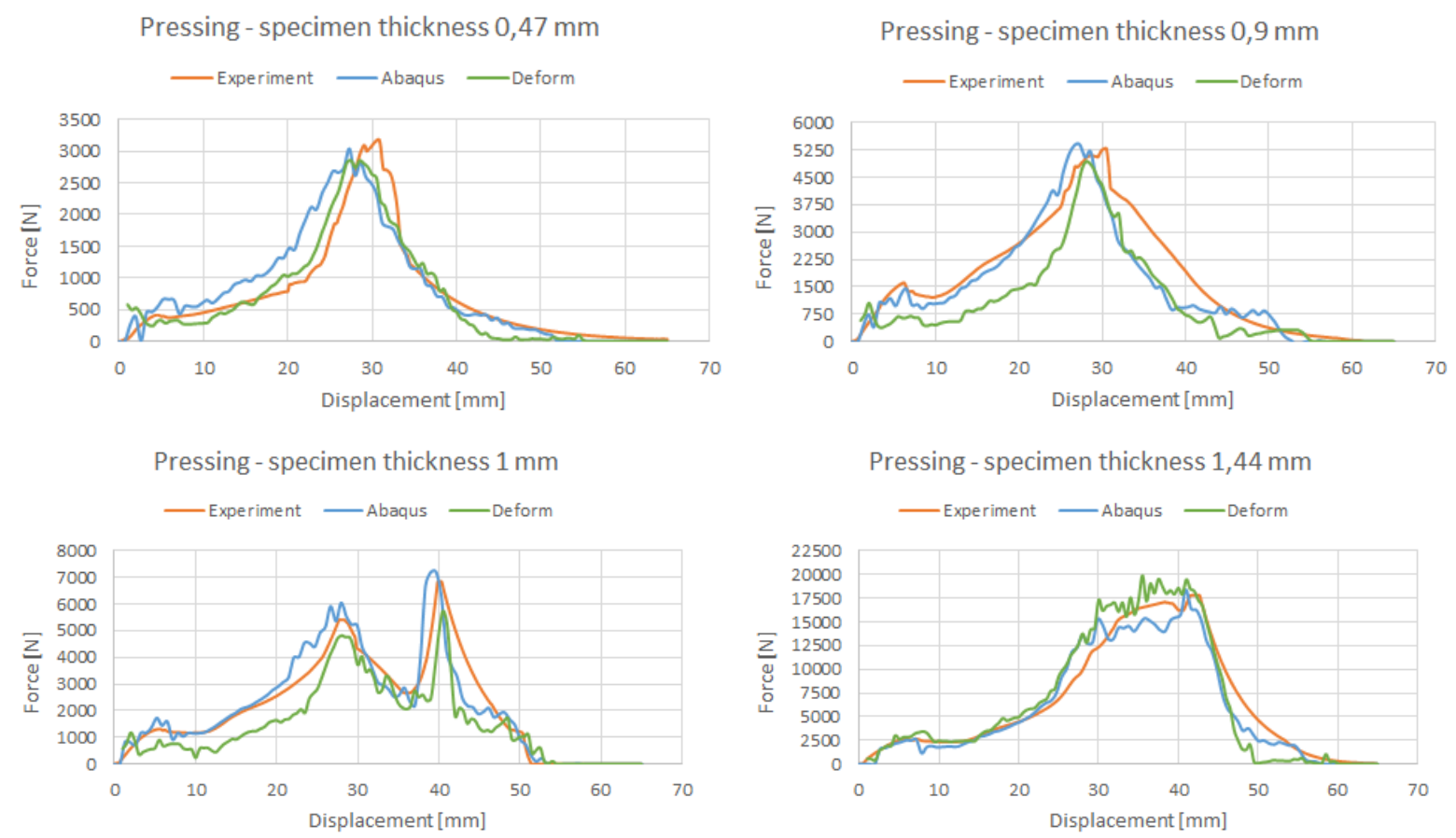

Fig. 9. Comparative characteristics of the stamping process

boundary conditions, process parameters, material model definitions and behaviour of the most advantageous FEM mesh types, there is a significant level of discrepancy between the compute packages used. Divergence between the obtained results, are due to the lack of possibility of using the same type of mesh in both programs. However, the use of solid type of mesh with high density in the Deform-3D, enables to obtain satisfactory results for the Abaqus software.

\section{CONCLUSIONS}

The experimental and numerical studies of the stamping process have shown relatively consistent results. It has been demonstrated that there are advanced numerical computation programs that allow for greater consistency of results Abaqus and lower - Deform-3D within a given type of issue. The use of numerical calculations is supported by the use of several independent validation capabilities in regard to actual experimental research. Within the framework of the conducted studies, changes in the obtained results of the stamping forces have been proved as a result of changes in the thickness of the samples with constant displacement of the stamp. The Abaqus program has proved more reliable computing software, with a maximum divergence of just over 5
$\%$ compared to the experiment, and Deform-3D about $16 \%$, both for $1 \mathrm{~mm}$ thick sample. The study showed the essence of sample's thickens influence on the height value change, which was obtained due to stamping process. The quality of the obtained results constitutes about properly prepared numerical model. It has been shown that it is possible to accurately simulate the numerical calculations of actual processes (for the stamping process of aluminum samples).

\section{REFERENCES}

1. Chang Q., Li D., Peng Y., Zeng X.: Experimental and numerical study of warm deep drawing AZ31 Magnesium alloy sheet, International Journal of Machine Tools and Manufacture 47, 436-443, 2007.

2. Chen F., Huong T., Chang C.: Deep drawing of square cups with magnesium alloy AZ31 sheets, International Journal of Machine tools and Manufacture 43, 1553-1559, 2003.

3. Isik K., Silva M., Tekkaya A., Martins P.: Formability limits by fracture in sheet metal forming, Journal of Materials Processing Technology 214, 1557-1565, 2014.

4. Jin J., Wang X., Deng L., Luo I.: A single - step hot stamping forging process for aluminum alloy shell parts with non-uniform thickness, Journal of Materials Processing Technology 228, 170-178 (2016). 
5. Lonkwic P., Różyło P., Dębski H.: Numerical and experimental analysis of the progressive gear body with the use of finite-element method. Eksploatacja i Niezawodnosc - Maintenance and Reliability 2015, vol. 17, no. 4, p.544-550.

6. Lonkwic P., Różyło P.: Theoretical and experimental analysis of loading impact from the progressive gear on the lift braking distance with the use of the free fall method. Advances in Science and Technology - Research Journal, 10 (30), 2016, 103-109.

7. Mohamed M., Lin J., Foster A., Dean T., Dear J.: A new test design for assessing formability of materials in hot stamping, Procedia Engineering 81, 1689-1694, 2014.

8. Mori K., Nishijima S., Tan C.J.: Two stage cold stamping of magnesium alloy cups having small corner radius, International Journal of Machine tools and Manufacture 49, 767-772, 2009.

9. Pereira M., Rolfe B.: Temperature conditions during cold sheet metal stamping, Journal of Materials Processing Technology 214, 1749-1758, 2014.

10. Romanowski W. P.: Poradnik obróbki plastycznej na zimno. WNT, Warszawa, 1976.

11. Rozylo P.: Optimization of I-section profile design by the finite element method. Advances in Science and Technology - Research Journal, 10 (29), 2016, 52-56.

12.Zienkiewicz O.C., Taylor R.L.: Finite Element Method (5th Edition) Volume 2 - Solid Mechanics, Elsevier, 2000. 